\title{
Producción científica de enfermería en el trasplante de células madre hematopoyéticas de sangre de cordón umbilical
}

\author{
Scientific production of nursing on transplantation of stem cells \\ hematopoietic of cord blood
}

\section{Produção científica da enfermagem sobre transplante de células-tronco hematopoéticas de sangue do cordão umbilical}

\section{Magda Maria Barbosa da Silva ${ }^{1}$, Isabelle Campos de Azevedo, ${ }^{2}$ Isabel Cristina Amaral de Sousa Rosso Nelson, ${ }^{3}$ Isabel Cristina Araújo Brandão,, ${ }^{4}$ Ricardina Oliveira da Silva, ${ }^{5}$ Marcos Antonio Ferreira Júnior6}

\footnotetext{
${ }^{1}$ Enfermeira, Centro Universitário FACEX, Natal/RN, Brasil. Universidade Federal do Rio Grande do Norte, Centro de Ciências da Saúde, Departamento de Enfermagem.

2Enfermeira, Mestranda do Programa de Pós-Graduação em Enfermagem, Universidade Federal do Rio Grande do Norte, Natal/RN, Brasil.

${ }^{3}$ Enfermeira, Coordenadora do Curso de Graduação em Enfermagem do Centro Universitário FACEX, Natal/RN, Brasil.

${ }^{4}$ Enfermeira, Professora do Curso de Graduação em Enfermagem do Centro Universitário FACEX, Natal/RN, Brasil.

${ }^{5}$ Enfermeira, Centro Universitário do Rio Grande do Norte, Natal/RN, Brasil.

${ }^{6}$ Enfermeiro. Doutor em Saúde e Desenvolvimento pela Universidade Federal do Mato Grosso do Sul.

Professor do curso de Graduação em Enfermagem e Professor Permanente da Pós-Graduação em

Enfermagem (Mestrado acadêmico e Doutorado) do Departamento de Enfermagem da Universidade Federal do Rio Grande do Norte. Líder Grupo de Pesquisa "Núcleo de Estudos e Pesquisas em Enfermagem Clínica (NEPEC)". Natal/RN, Brasil.
}

Cómo citar este artículo en edición digital: Silva, M.Mà.B., Azevedo, I.C., Nelson I.C.A.S.R., Brandão,I.C.A., Silva,R.O., \& Júnior, Ferreira, M.A. (2018). Producción científica de enfermería en el trasplante de células madre hematopoyéticas de sangre de cordón umbilical. Cultura de los Cuidados (Edición digital), 22(51). Recuperado de <http://dx.doi.org/10.14198/cuid.2018.51.19>

Correspondencia: Centro Universitário FACEX, Natal/RN, Brasil. Universidade Federal do Rio Grande do Norte, Centro de Ciências da Saúde, Departamento de Enfermagem. Avenida Salgado Filho, S/N, Lagoa Nova, Natal/RN, Brasil. CEP: 59078-970. Telefone: (84) 981910900.

Correo electrónico: magdagoncalves7@hotmail.com Recibido: 17/11/2017; Aceptado: 12/03/2018. 


\section{RESUMEN}

Introducción: El trasplante de células madre hematopoyéticas (TCMH) es un procedimiento que reemplaza las células enfermas a las células sanas, a través de la infusión de células madre hematopoyéticas. Objetivo: Identificar en la literatura las publicaciones de enfermería que se ocupan de la sangre de cordón umbilical La sangre (UCB) TCMH. Método: Se trata de una revisión integradora, para lo cual allanó a través de bases de datos electrónicas: Biblioteca Virtual en Salud, Biblioteca Nacional de Medicina (PubMed/MEDLINE), Science Direct y Scopus. Se establecieron los siguientes criterios de inclusión: los estudios disponibles en cualquier idioma, los estudios que abordaron la sangre del cordón umbilical TPH y el estudio en su totalidad. Resultados: El proceso de búsqueda electrónica de los estudios dieron como resultado un total de 978 estudios, de los cuales cinco fueron incluidas en la muestra de revisión. Los estudios seleccionados abordan el conocimiento del personal de enfermería en el trasplante de SCU, la recogida y almacenamiento de sangre del cordón umbilical y el Banco de SCU. Conclusión: Este estudio proporciona la percepción de la importancia del papel de la enfermera en TPH de SCU, como su compromiso con el equipo de los bancos públicos UCB es importante para lograr mejores resultados al aumentar el número de donantes y el aumento de la satisfacción del cliente y sus familias.

Palabras clave: Trasplante de células madre hematopoyéticas; Trasplante de médula ósea; Cordón umbilical; Enfermería.

\section{ABSTRACT}

Introduction: Hematopoietic stem cell transplantation (HSCT) is a procedure that replaces diseased cells with healthy cells by infusing hematopoietic stem cells. Objective: To identify in the literature the nursing publications that addresses HSCT of Umbilical Cord Blood (UCB). Method: This is an integrative review, which has been searched through electronic databases: Virtual Health Library, National Library of Medicine (PUBMED/MEDLINE), Science Direct and SCOPUS. The following inclusion criteria were established: studies available in any language, studies addressing HSCT of umbilical cord blood and a study published in its entirety. Results: The electronic search process of the studies resulted in a total of 978 studies, of which five comprised the review sample. The selected studies addressed the nurses' knowledge about SCU transplantation, the collection and storage of SCU and the SCU database. Conclusion: The present study provided an insight into the importance of the role of nurses in HSCTWC, since their commitment to the team of SCU public banks is important to achieve better results, with a larger number of donors and greater customer satisfaction And their families.

Keywords: Hematopoietic stem cell transplantation; Bone marrow transplantation; Umbilical cord; Nursing.

\section{RESUMO}

Introdução: O Transplante de Células-Tronco Hematopoéticas (TCTH) é um procedimento que substitui células doentes por células sadias, por meio da infusão de células-tronco hematopoéticas. Objetivo: Identificar na literatura as publicações da enfermagem que abordem o TCTH de Sangue de Cordão Umbilical (SCU). Método: Trata-se de uma revisão integrativa, para qual se realizou buscas por meio das bases de dados eletrônicas: Biblioteca Virtual em Saúde, National Library of Medicine (PUBMED/MEDLINE), Science Direct e SCOPUS. Foram estabelecidos os seguintes critérios de inclusão: estudos disponíveis em qualquer idioma, estudos que abordassem o TCTH de sangue de cordão umbilical e estudo publicado na íntegra. Resultados: O processo de busca eletrônica dos estudos resultou em um total de 978 estudos, dos quais cinco compuseram a amostra da revisão. Os estudos selecionados abordaram o 
conhecimento dos enfermeiros sobre o transplante de SCU, a coleta e armazenamento do SCU e o banco de SCU. Conclusão: O presente estudo proporcionou a percepção da importância do papel do enfermeiro no TCTH de SCU, visto que seu empenho junto à equipe dos bancos públicos de SCU é importante para alcançar melhores resultados, com a ampliação do número de doadores e maior satisfação dos clientes e seus familiares.

Palavras-chave: Transplante de células-tronco hematopoéticas; Transplante de medula óssea; Cordão umbilical; Enfermagem.

\section{INTRODUÇÃO}

O Transplante de Células-Tronco Hematopoéticas (TCTH) é um procedimento que substitui células doentes por células sadias por meio da infusão de Células-Tronco Hematopoéticas (CTH). Esse procedimento consiste em uma opção terapêutica agressiva para um conjunto de doenças oncohematológicas e imunológicas herdadas geneticamente ou adquiridas (Passweg et al, 2012; Zago, Falcão \& Pasquini, 2012; Hoffbrand \& Moss, 2013; Azevedo et al, 2016) . O termo TCTH é generalizado e engloba o Transplante de Medula Óssea (TMO), no qual as células são coletadas da medula óssea (Hoffbrand \& Moss, 2013). O transplante alogênico envolve a utilização de CTH de doador aparentado ou não. Contudo, deve haver compatibilidade do Antígeno Leucocitário Humano, do inglês Human Leukocyte Antigen (HLA) entre receptor e doador. E o singênico é um tipo de transplante alogênico, neste caso o doador e o receptor são irmãos gêmeos idênticos. A coleta das CTH para estes dois tipos de transplante pode ser de medula óssea, de sangue periférico e de Sangue do Cordão Umbilical (SCU) (Hoffbrand \& Moss, 2013).

Para a maior parte dos pacientes com indicação de transplante alogênico é possível encontrar uma unidade de SCU na atualidade, pois a maior vantagem dessa fonte de CTH é a possibilidade de transplantar com incompatibilidade de HLA. O aumento do risco de falha no enxerto e de Doença do Enxerto Contra o Hospedeiro pode estar ligado a um grau elevado de incompatibilidade de unidades de SCU, por outro lado nos casos de leucemia agudas em crianças elas obtêm um resultado de enxerto positivo com menores índices de recaída (Cohen et al, 2011).

O transplante alogênico de CTH tem sido uma modalidade de tratamento cada vez mais utilizada nos últimos 45 anos para a cura de diversas doenças malignas hematológicas e outras doenças genéticas, como a doença falciforme e algumas imunodeficiências primárias (Rivero-Jiménez, 2013). Tal tipo de transplante é limitado pelo número reduzido de doadores compatíveis, e encontra menos doadores para pacientes provenientes de países em desenvolvimento e de minorias étnicas (Cohen et al, 2011), dessa maneira as CTH do SCU se configuram como uma alternativa de tratamento para pacientes em fila de espera para о TCTH.

Os profissionais de saúde, especialmente os enfermeiros, devem conhecer as fontes de CTH, a compatibilidade ABO e HLA, o tratamento dado às células, o regime de condicionamento e as estratégias de transplante com vistas a alta qualidade na promoção de cuidados e segurança do paciente. O enfermeiro é responsáveis por monitorar o receptor durante a infusão, o transplante propriamente dito, observar a pressão arterial, a temperatura, a frequência cardíaca, a frequência respiratória, identificar a presença de reação hemolítica aguda, a saturação de oxigênio caso o receptor apresente alguma alteração no quadro respiratório, sintomas de sobrecarga volêmica e também choque anafilático. Na presença deste último evento o enfermeiro deve diminuir ou até parar a infusão, notificar o médico imediatamente, e se necessário administrar medicações e oxigenoterapia, conforme protocolo/prescrição (Curcioli \& Carvalho, 2010; Lima \& Bernardino, 2014).

Diante desse contexto e por considerar que a enfermagem atua diretamente em todas as fases do processo de TCTH, o presente estudo teve como objetivo identificar na literatura as publicações de enfermagem que abordam o TCTH do sangue de cordão umbilical.

\section{MÉTODO}

Trata de uma revisão integrativa da literatura que para sua elaboração seguiu as seguintes etapas: $1^{\mathrm{a}}$ ) elaboração da questão norteadora, $2^{\mathrm{a}}$ ) 
busca na literatura, $3^{\mathrm{a}}$ ) coleta de dados, $4^{\mathrm{a}}$ ) análise crítica dos estudos incluídos, $5^{\text {a }}$ ) discussão dos resultados e $6^{\mathrm{a}}$ ) apresentação da revisão integrativa (Souza, Silva \& Carvalho, 2010). Para nortear a presente revisão foi formulada a seguinte questão de pesquisa: Quais as temáticas discutidas pela enfermagem sobre o TCTH de SCU nas publicações encontradas na literatura?

Para responder ao questionamento foi elaborado um protocolo específico para fins desse estudo (APÊNDICE 1) e realizou-se uma busca na literatura entre os meses de agosto e setembro de 2015 por meio das bases de dados eletrônicas: Biblioteca Virtual em Saúde (BVS), National Library of Medicine (PUBMED/MEDLINE), Science Direct e SCOPUS. Para a seleção das publicações foram estabelecidos os seguintes critérios de inclusão: estudos disponíveis em qualquer idioma, que abordassem o TCTH de sangue de cordão umbilical e publicados na íntegra. Dessa maneira, foram excluídos os editoriais, cartas ao editor, resumos, opinião de especialistas, revisões, resenhas, livros, capítulos de livros, teses e dissertações. Não houve recorte temporal para a seleção dos estudos, uma vez que se considerou importante pesquisar todas as evidências científicas disponíveis nas bases de dados.

Para coletar as informações das publicações selecionadas foi utilizado um formulário estruturado, com questões referentes às bases de dados, autores, título, país de realização do estudo, ano, objetivo, tipo de estudo e principais resultados encontrados.

Para a busca das publicações foram utilizados os descritores indexados no Descritores em Ciências da Saúde (DeCS) e no Medical Subject
Headings (MeSH), respectivamente: transplante de células-tronco hematopoéticas (hematopoietic stem cell transplantation), cordão umbilical (umbilical cord) e enfermagem (nursing), cruzados por meio do operador booleano AND, a saber: 1\# AND 2\# AND 3\#.

Durante a coleta de dados os estudos foram pré-selecionados a partir da leitura minuciosa de títulos e resumos para identificar a relação com a questão norteadora proposta para a revisão e com os critérios de inclusão e exclusão adotados. Após isso foi realizada leitura na íntegra dos artigos pré-selecionados.

\section{DESENVOLVIMENTO}

O processo de busca eletrônica dos estudos nas bases de dados resultou em um total de 978 estudos, dos quais cinco foram selecionados para compor a amostra da revisão. Os artigos repetidos nas bases de dados foram excluídos, conforme observado na Figura 1. As informações colhidas foram digitalizadas em planilhas do Microsoft Excel ${ }^{\circledR} 2010$ e em seguida apresentadas em quadro.

Após análise detalhada dos artigos, verificouse que cinco exploravam o tema em questão e compuseram a amostra da pesquisa. Destes, três foram recuperados da SCOPUS, um da Science Direct e um da PUBMED/MEDLINE. No Quadro 1 são apresentados os autores, títulos, país e ano de publicação dos artigos selecionados, assim como seus respectivos objetivos, resultados e tipo de estudo. 


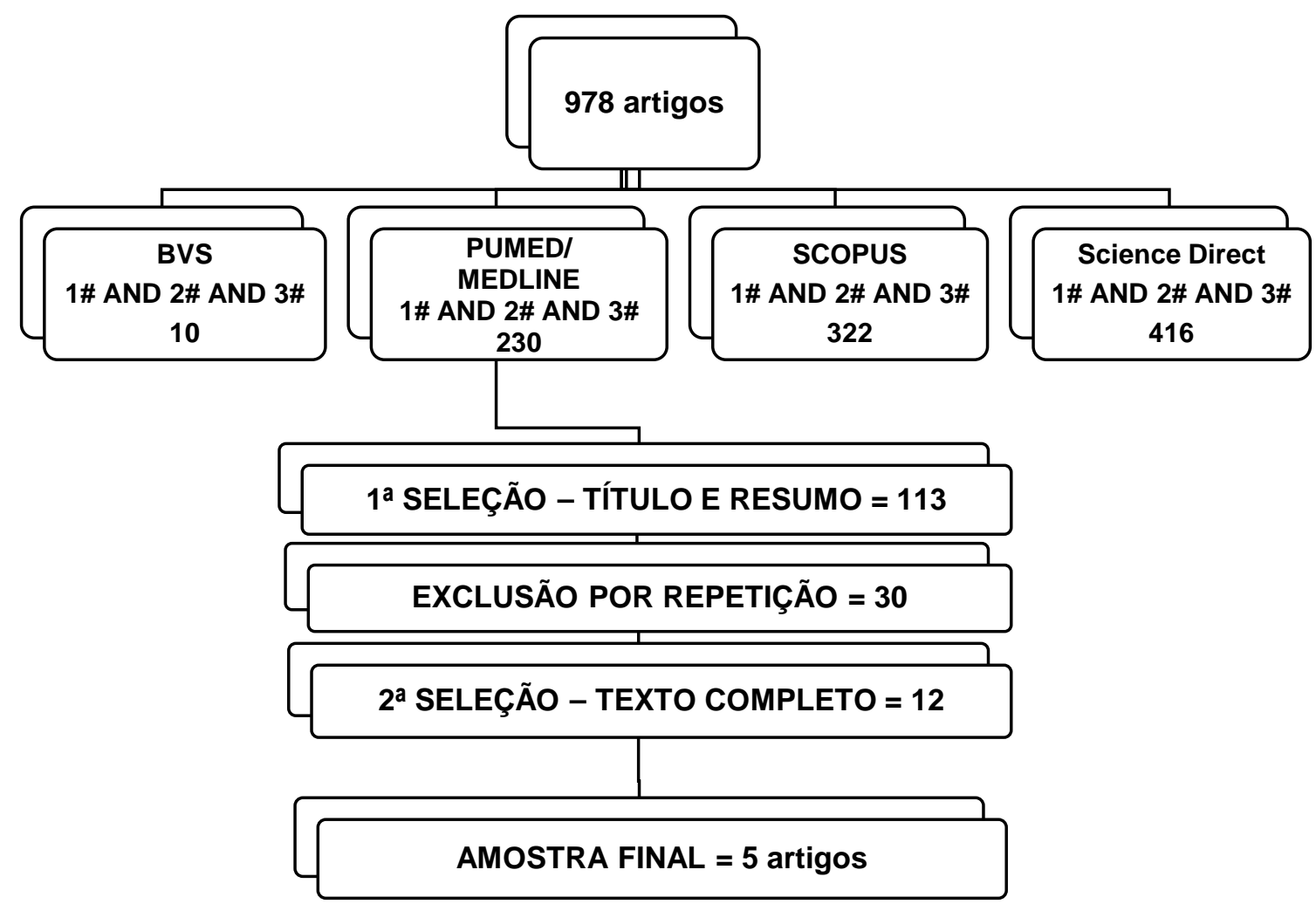

Figura 1. Síntese do processo de extração dos dados

Quadro 1 - Caracterização da amostra do estudo de acordo com os autores, título, país, ano, tipo de estudo, objetivo e resultados. Natal/RN, $2015(n=5)$. 


\begin{tabular}{|c|c|c|c|}
\hline $\begin{array}{c}\text { Autores, Título, Base de } \\
\text { dados, País e Ano }\end{array}$ & Tipo de Estudo & Objetivo & Resultados \\
\hline $\begin{array}{l}\text { - Curcioli ACJV, Carvalho EC. } \\
\text { - Infusão de células-tronco } \\
\text { hematopoéticas: tipos, } \\
\text { características, reações adversas } \\
\text { e transfusionais e implicações } \\
\text { para a enfermagem. } \\
\text { - SCOPUS } \\
\text { - Brasil/2010. }\end{array}$ & $\begin{array}{l}\text { Estudo } \\
\text { epidemiológico. }\end{array}$ & $\begin{array}{l}\text { Identificar as } \\
\text { reações adversas e } \\
\text { transfusionais que } \\
\text { podem ocorrer } \\
\text { durante a infusão e } \\
\text { os cuidados de } \\
\text { enfermagem } \\
\text { inerentes ao } \\
\text { procedimento. }\end{array}$ & $\begin{array}{l}\text { Registrar todo o processo de } \\
\text { infusão favorece a } \\
\text { compreensão da assistência } \\
\text { de enfermagem prestada, } \\
\text { bem como o controle de } \\
\text { eventos adversos ocorridos } \\
\text { durante a infusão de CTH. }\end{array}$ \\
\hline $\begin{array}{l}\text { - Dinç H, Sahin NH. } \\
\text { - Pregnant women's knowledge } \\
\text { and attitudes about stem cells } \\
\text { and cord blood banking. } \\
\text { - SCOPUS } \\
\text { - Turquia/2009. }\end{array}$ & $\begin{array}{l}\text { Estudo descritivo } \\
\text { exploratório. }\end{array}$ & $\begin{array}{l}\text { Determinar } \\
\text { conhecimentos e } \\
\text { atitudes das } \\
\text { mulheres grávidas } \\
\text { em relação ao uso } \\
\text { de células-tronco e } \\
\text { de cordão sangue } \\
\text { em um banco de } \\
\text { sangue de } \\
\text { Istambul, Turquia. }\end{array}$ & $\begin{array}{l}\text { Os enfermeiros/parteiras } \\
\text { precisam estar bem } \\
\text { informados sobre os últimos } \\
\text { avanços do uso de células- } \\
\text { tronco e sangue do cordão } \\
\text { umbilical e desenvolver a sua } \\
\text { prática com habilidades nesta } \\
\text { área de atuação em especial. }\end{array}$ \\
\hline $\begin{array}{l}\text { - Marques DLOL. et al - } \\
\text { Celularidade do sangue de } \\
\text { cordão umbilical de gestantes } \\
\text { hipertensas: estudo caso- } \\
\text { controle. } \\
\text { - SCOPUS } \\
\text { - Brasil/2015. }\end{array}$ & $\begin{array}{l}\text { Estudo caso- } \\
\text { controle. }\end{array}$ & $\begin{array}{l}\text { Analisar a relação } \\
\text { entre celularidade } \\
\text { do sangue do } \\
\text { cordão umbilical e } \\
\text { placentário de } \\
\text { gestantes } \\
\text { hipertensas e não } \\
\text { hipertensas. }\end{array}$ & $\begin{array}{l}\text { A observação de fatores que } \\
\text { podem influenciar na } \\
\text { celularidade desse tipo de } \\
\text { sangue está incluída nas } \\
\text { inúmeras competências dos } \\
\text { enfermeiros que atuam nos } \\
\text { bancos de sangue que } \\
\text { coletam SCU. }\end{array}$ \\
\hline $\begin{array}{l}\text { - Santos SV. et al } \\
\text { - A cross-sectional study of } \\
\text { umbilical cord blood donor } \\
\text { profiles and their influence on } \\
\text { umbilical cord blood collection } \\
\text { in a Brazilian hospital. } \\
\text { - Science Direct } \\
\text { - Brasil/2011. }\end{array}$ & $\begin{array}{l}\text { Estudo } \\
\text { retrospectivo } \\
\text { qualitativo } \\
\text { descritivo. }\end{array}$ & $\begin{array}{l}\text { Descrever a } \\
\text { população de } \\
\text { doadores e avaliar } \\
\text { a melhor técnica de } \\
\text { coleta de sangue } \\
\text { do cordão } \\
\text { umbilical em } \\
\text { banco de sangue } \\
\text { do cordão } \\
\text { umbilical do } \\
\text { Hospital Israelita } \\
\text { Albert Einstein } \\
\text { (São Paulo, Brasil). }\end{array}$ & $\begin{array}{l}\text { O potencial doador efetivou a } \\
\text { doação de forma mais } \\
\text { frequente quando foi } \\
\text { abordado pelo profissional } \\
\text { enfermeiro que forneceu } \\
\text { instruções a respeito da } \\
\text { doação, da necessidade de } \\
\text { responder a um formulário } \\
\text { com questões clínicas e para } \\
\text { assinar um consentimento } \\
\text { informado. }\end{array}$ \\
\hline $\begin{array}{l}\text { - Hatzistilli H. et al. } \\
\text { - Health Professionals' } \\
\text { knowledge and attitude towards } \\
\text { the Umbilical Cord Blood } \\
\text { donation in Greece. } \\
\text { - PUBMED/ } \\
\text { MEDLINE } \\
\text { - Grécia/2014. }\end{array}$ & $\begin{array}{l}\text { Estudo transversal } \\
\text { exploratório. }\end{array}$ & $\begin{array}{l}\text { Investigar o nível } \\
\text { de conhecimento } \\
\text { dos profissionais } \\
\text { de saúde, suas } \\
\text { atitudes sobre } \\
\text { doação SCU e as } \\
\text { fontes de } \\
\text { fornecimento. }\end{array}$ & $\begin{array}{l}\text { Enfermeiros devem estar } \\
\text { cientes dos conhecimentos } \\
\text { específicos sobre os bancos } \\
\text { de SCU. }\end{array}$ \\
\hline
\end{tabular}


Houve uma predominância das publicações nacionais de Enfermagem sobre TCTH do SCU com três estudos que compuseram os dados da amostra publicados nos anos de 2010, 2011 e 2015. Os outros estudos foram produzidos na Turquia (um) no ano de 2009 e na Grécia (um) no ano de 2014. Quanto às pesquisas nacionais analisadas por estado, duas foram realizadas no estado de São Paulo e uma no estado do Rio de Janeiro. As pesquisas internacionais foram provenientes de Istambul na Turquia e em Atenas na Grécia.

De acordo com a base de dados pesquisada, foram encontrados três dos estudos na SCOPUS, um na Science Direct e um na PUBMED/MEDLINE. Dos cinco artigos encontrados, todos estavam vinculados a pesquisas desenvolvidas por grupos de pesquisa em universidades. Dos trabalhos selecionados, um foi classificado como estudo epidemiológico, um como estudo descritivo exploratório, um como estudo de caso-controle, um estudo retrospectivo qualitativo descritivo e um como estudo transversal exploratório. Entre os temas encontrados nas publicações, resultou na predominância daqueles relacionados à importância do conhecimento dos enfermeiros sobre o TCTH de SCU, subsequentemente sobre importância dos conhecimentos sobre a coleta e armazenamento do SCU e os conhecimentos sobre o banco de SCU.

\section{Conhecimento dos enfermeiros sobre o TCTH de SCU}

O papel do enfermeiro no contexto do TCTH do SCU é relevante em todas as fases da utilização do SCU, com início na captação de doadores até a alta hospitalar. O enfermeiro é o profissional que tem um relacionamento direto com o paciente, por isso há uma extrema importância da assistência de enfermeiros com conhecimentos específicos neste serviço, pois este profissional atua como ligação e comunicação entre doadores, médicos, familiares e pacientes (Barini, Ferraz, Acácio \& Machado, 2011; Lima \& Bernardino, 2014). É necessário estar bem informado por meio dos últimos estudos sobre células-tronco e SCU de forma a contribuir com o desenvolvimento de sua habilidade nesta prática tão específica (Hatzistilli et al, 2014). Para isso, é necessário que o enfermeiro obtenha conhecimento sobre TCTH de SCU, pois é este o profissional que tem contato direto com o paciente, e em caso de alguma reação no processo do TCTH do SCU, o mesmo saberá a conduta correta a tomar, pois a elaboração do plano terapêutico é de sua competência.

Os enfermeiros que trabalham em unidades de doação de sangue têm mais informações sobre doação do SCU do que outros profissionais, por meio de programas de educação continuada. Em menor número, alguns profissionais relatam ter adquirido conhecimento por conversas com pacientes que necessitam realizar o TMO (Marinalva \& Tenório, 2010).

\section{Conhecimentos sobre a coleta e armazenamento do SCU}

O Enfermeiro por participar de todas as etapas do TCTH do SCU, deve estar informado e atualizado sobre a coleta e armazenamento do SCU, pois antes da coleta é realizada uma triagem com a gestante para avaliar se ela se enquadra nos critérios de doação para bancos públicos ou privados. Para que a gestante faça doação do SCU para o banco público deve ter idade entre 18 e 36 anos, ter pelo menos duas consultas do pré-natal registradas, não possuir histórico familiar de doenças neoplásicas e hematológicas, não ter doenças que interfiram na vitalidade da placenta, hipertensão, idade gestacional (IG) acima de 35 semanas e o peso fetal acima de $2 \mathrm{~kg}$. Já para o banco privado, a gestante tem que ter uma IG $\geq 32$ semanas, sem descrição para idade materna, tamanho e peso do feto (Marinalva \& Tenório, 2010; Marques, Oliveira, Izu, Bouzas, \& Braga, 2015).

São realizados exames sorológicos de HIV I e II, Hepatite A, B e C, Toxoplasmose, Citomegalovírus, doença de Chagas, sífilis e eletroforese de hemoglobina antes da coleta do sangue. É realizada então a coleta propriamente dita, que pode ser com placenta intrauterina ou extrauterina e mista, em qualquer tipo de parto (Brasil, 2004; Voltarelli, Pasquini \& Ortega, 2009; Santos, Marti, Ribeiro, Conti \& Barros, 2011).

A coleta do SCU é realizada por médico ou enfermeiro devidamente treinado e capacitado em sistema fechado após o nascimento do bebê, no terceiro período do parto o cordão umbilical é clampeado o mais próximo do bebê, realiza-se a 
assepsia com clorexidina a 0,5\% de um seguimento do cordão e antes do desprendimento da placenta, punciona-se a veia umbilical com agulha que deve estar conectada a bolsa de coleta. A placenta fica em uma altura mais elevada em relação à bolsa de coleta para melhor fluidez do sangue por gravidade. Todo procedimento deve ser estéril (Barini, Ferraz, Acácio \& Machado, 2011; Santos, Marti, Ribeiro, Conti \& Barros, 2011). Só é aceito o SCU para processamento se o número de células nucleadas da coleta for igual a $5 \times 10^{8}$ segundo a Agência Nacional de Vigilância Sanitária por meio da Resolução da Diretoria Colegiada RDC $n^{\circ}$ 56. Já o Instituto Nacional do Câncer institui o número total de células nucleadas igual ou superior a 7,5 x $10^{8}$, e como o volume mínimo colhido de $70 \mathrm{ml}$ (Santos, Marti, Ribeiro, Conti \& Barros, 2011; Marques, Oliveira, Izu, Bouzas \& Braga, 2015).

A unidade de SCU deve ser armazenada em uma caixa refrigerada, com monitorização da temperatura que pode variar de 4 a $24^{\circ} \mathrm{C}$. A RDC No 153/2004 exige que o intervalo entre a coleta e o processamento nos bancos de sangue seja inferior a 48 horas (Barini, Ferraz, Acácio \& Machado, 2011; Brasil, 2004).

\section{Conhecimentos sobre o banco de SCU}

Existe confirmação científica de que o Sangue do Cordão Umbilical e Placentário consiste em uma fonte de células progenitoras hematopoéticas em grande quantidade, que podem ser criopreservadas para no futuro ser descongeladas sem perda da eficácia de formação de colônias in vitro (Mendes-Takao, Diaz-Bermúdez, Deffune \& Santis, 2010). Em 1992 em Nova York, foi fundado o primeiro Banco de Sangue de Cordão Umbilical e Placentário (BSCUP) de caráter público. Atualmente, existem dois tipos de BSCUP reconhecidos pela legislação brasileira, o privado e o público. O BSCUP privado permite o congelamento das CTH do SCU para uso autólogo ou familiar (Ballen, Barker, Stewart, Greene \& Lane, 2008) e o público fornece SCUP para uso alogênico não-aparentado, produtos de doação voluntária, sigilosa e com consentimento da mãe. Atualmente, existem 13 BSCUP públicos no Brasil, dos quais um se encontra na região Norte, dois na região Nordeste, seis na região Sudeste, três no Sul e um no Centro-Oeste (Brasil, 2015).

\section{CONCLUSÃO}

O presente estudo tornou possível evidenciar a importância do papel do enfermeiro no TCTH de SCU, visto que seu empenho junto à equipe dos bancos públicos de sangue do cordão umbilical e placentário é importante para alcançar melhores resultados, com a ampliação do número de doadores e maior satisfação dos clientes e seus familiares.

Vários cordões umbilicais são desprezados após o parto e junto com eles a esperança de muitos pacientes com doenças hematológicas malignas que aguardam um TCTH para cura. É necessária a divulgação da rica fonte de vida que o SCU representa, para que o número de doações aumente.

Com isto, o estudo trouxe um leque de atribuições ao enfermeiro que presta assistência neste serviço tão específico, das quais o fornecimento de informações sobre a doação do SCU a população é o primeiro e mais importante passo para que se torne possível esse tipo de transplante. Da mesma forma, o conhecimento sobre os critérios de doação, para garantia de uma coleta com celularidade adequada, haja vista que tal procedimento é extremamente importante para que a unidade de SCU seja confiável para o enxerto, como também o armazenamento seja realizado em tempo hábil.

\section{REFERÊNCIAS}

Azevedo, I. C., Menezes, R. M. P., Medeiros, S. M., Carvalho, D. P.S. R. P., Cruz, G. K. P., Câmara, P. F. M., Silva, R. C. L., Oliveira, A. A., Lima, J. V. H., Aquino, L. A. P., \& Ferreira Júnior, M. A. (2016). Hematopoietic stem cell transplantation based on the transdisciplinary care. International Archives of Medicine. 9(28),1-6.

Ballen, K. K., Barker, J. N., Stewart, S. K., Greene, M. F., \& Lane, T. A. (2008). Collection and preservation of cord blood for personal use. 
Biology of Blood and Marrow Transplantation. 14(3), 356-63.

Barini, R., Ferraz, U. C., Acácio, G. L., \& Machado, I. N. (2011). O intervalo de tempo entre coleta e processamento do sangue de cordão umbilical influencia na qualidade da amostra? Einstein. 9(2), 207-211.

Brasil. Ministério da Saúde. Agência Nacional de Vigilância Sanitária. (2004). Resolução-RDC N ${ }^{\circ}$ 153, de 14 de junho de 2004. Determina o Regulamento Técnico para os procedimentos hemoterápicos, incluindo a coleta, o processamento, a testagem, o armazenamento, o transporte, o controle de qualidade e o uso humano de sangue, e seus componentes, obtidos do sangue venoso, do cordão umbilical, da placenta e da medula óssea. Brasília (DF): Ministério da Saúde.

Brasil. Ministério da Saúde. Instituto Nacional de Câncer José Alencar Gomes da Silva (INCA). (2015). Rede BrasilCord. Rio de Janeiro: INCA.

Cohen, Y. C., Scaradavou, A., Stevens, C. E., Rubinstein, P., Gluckman, E., Rocha, V., Horowitz, M. M., Eapen, M., Nagler, A., Shpall, E. J., Laughlin, M. J., Daniely, Y., Pacheco, D., Barishev, R., Olmer, L., \& Freedman, L. S. (2011). Factors affecting mortality following myeloablative cord blood transplantation in adults: a pooled analysis of three international registries. Bone Marrow Transplant. 46(1), 70-6.

Curcioli, A. C. J. V., \& Carvalho, E. C. (2010). Infusão de células-tronco hematopoéticas: tipos, características, reações adversas e transfusionais e implicações para a enfermagem. Rev LatinoAm. Enfermagem. 18(4).

Dinç, H., \& Sahin, N. H. (2009). Pregnant women's knowledge and attitudes about stem cells and cord blood banking. International Nursing Review. 56(2), 250-6.

Hatzistilli, H., Zissimopoulou, O., Galanis, P., Siskou, O., Prezerakos, P., Zissimopoulos, A., \& Kaitelidou, D. (2014). Health professionals' knowledge and attitude towards the umbilical cord clood donation in Greece. Hippokratia. 18(2), 110-5.

Hoffbrand, A. V., \& Moss, P. A. H. (2013). Fundamentos em hematologia. Porto Alegre: Artmed.

Lima, K., \& Bernardino, E. (2014). O cuidado de enfermagem em unidade de transplante de células-tronco hematopoéticas. Texto Contexto Enfermagem. 23(4): 845-53.

Marques, D. L. O. L., Oliveira, B. G. R. B., Izu, M., Bouzas, L. F. S., \& Braga, F. H. P. (2015). Celularidade do sangue de cordão umbilical de gestantes hipertensas: estudo caso-controle. Online braz J nurs. 14(2), 121-31.

Mendes-Takao, M. R., Diaz-Bermúdez, X. P., Deffune, E., \& Santis, G. C. (2010). Bancos de sangue de cordão umbilical e placentário para uso familiar, de caráter privado, no Brasil subsídios técnicos, legais e éticos para uma análise de implementação. Rev Bras Hematol Hemoter. 32(4), 317-28.

Passweg, J. R., Halter, J., Bucher, C., Gerull, S., Heim, D., Rovó, A., Buser, A., Stern, M., \& Tichelli, A. (2012). Hematopoietic stem cell transplantation: a review and recommendations for follow-up care for the general practitioner. Swiss Med Wkly, 142, 1-15.

Rivero-Jiménez, R. A. (2013). Razones para un banco de sangre de cordón umbilical en el Instituto de Hematología e Inmunología de Cuba. Revista Cubana de Hematol Inmunol y Hemoter. 30(1), 4-10.

Santos, S. V., Marti, L., Ribeiro, A. A. F., Conti, F., \& Barros, S. M. (2011). A cross-sectional study of umbilical cord blood donor profiles and their influence on umbilical cord blood collection in a Brazilian hospital. Cytotherapy. 13, 1120-7.

Silva, M. O., \& Tenório, L. C. T. (2010). Banco de sangue de cordão umbilical e placentário no Brasil. Ensaios e Ciência: Ciências Biológicas, Agrárias e da Saúde. 14(2), 124-41.

Souza, M. T., Silva, M. D., \& Carvalho, R. (2010). Revisão integrativa: o que é e como fazer. Einstein. 8(1), 102-6.

Voltarelli, J. C., Pasquini, R., \& Ortega, E. T. (2009). Transplante de células-tronco hematopoéticas. São Paulo: Atheneu.

Zago, M. A., Falcão, R. P., \& Pasquini, R. (2012). Tratado de hematologia. São Paulo: Atheneu. 